NBER WORKING PAPER SERIES

\title{
CAN PORTFOLIO REBALANCING EXPLAIN THE DYNAMICS OF EQUITY RETURNS, EQUITY FLOWS, AND EXCHANGE RATES?
}

\author{
Harald Hau \\ Hélène Rey \\ Working Paper 10476 \\ http://www.nber.org/papers/w10476 \\ NATIONAL BUREAU OF ECONOMIC RESEARCH \\ 1050 Massachusetts Avenue \\ Cambridge, MA 02138 \\ May 2004
}

We are grateful to Fabio Canova, Bernard Dumas, Rich Lyons and Gregorios Souriounis for very helpful comments. We thank also the Fondation Banque de France for financial support. The paper is part of the project "Exchange Rates, International Relative Prices, and Macroeconomic Models", funded by the ESRC (grant no.L138 25 1043), and of the RTN programme "The Analysis of International Capital Markets: Understanding Europe's Role in the Global Economy", funded by the European Commission contract no. HPRN-CT-1999-00067).The views expressed herein are those of the author(s) and not necessarily those of the National Bureau of Economic Research.

(C2004 by Harald Hau and Hélène Rey. All rights reserved. Short sections of text, not to exceed two paragraphs, may be quoted without explicit permission provided that full credit, including $\odot$ notice, is given to the source. 
Can Portfolio Rebalancing Explain the Dynamics of Equity Returns, Equity Flows, and Exchange Rates?

Harald Hau and Hélène Rey

NBER Working Paper No. 10476

May 2004

JEL No. F30, F31

\section{ABSTRACT}

We explore whether the pattern of international equity returns, equity portfolio flows, and exchange rate returns are consistent with the hypothesis that (unhedged) global investors rebalance their portfolio in order to limit their exchange rate exposure when there are (1) relative equity return and (2) exchange rate shocks. We also explore whether (3) equity flow shocks influence the exchange rates and relative equity prices. In the estimation of the VAR system we do not impose any causal ordering upon the primitive shocks, but instead identify the system based on theoretical priors about the contemporaneous conditional correlations between the three variables. International data for the five largest equity markets are consistent with a theory in which equity returns and portfolio rebalancing are an important source of exchange rate dynamics.

Harald Hau

Department of Finance

Boulevard de Constance

77305 Fontainebleau Cedex

France

harald.hau@insead.edu

Helene Rey

Department of Economics

Woodrow Wilson School

Princeton University

Princeton, NJ 08544

and NBER

hrey@princeton.edu 


\section{Introduction}

Portfolio rebalancing motives are an old topic in exchange rate theory (Kouri (1982), Branson and Henderson (1985)). While the earlier literature mostly lacks modern microfoundations, its emphasis on capital markets resonates more than ever with the stylized facts of international finance. Gross capital flows and particularly equity flows have grown tremendously over the last two decades. ${ }^{1}$ And these equity portfolio flows have arguably become an important determinant of the short-run supply and demand of foreign exchange (FX) balances.

This paper examines whether the data on equity returns, equity flows, and exchange rate returns are supportive of a portfolio rebalancing channel. We argue that the portfolio rebalancing channel implies a set of conditional correlations between these variables which can be confronted with the data. Equity return and exchange rate data are straightforward to obtain. The best public data on international equity flows come from the U.S. Treasury (TIC data) and measure bilateral flows between the U.S. and a large number of foreign countries. We focus here on the 5 largest equity markets outside the U.S., namely France, Germany, Japan, Switzerland and the U.K. for the period January 1990 to September 2003.

A basic econometric problem with any system of simultaneously determined variables is the identification of primitive shocks. Frequently this problem is addressed by imposing a causal ordering between variables. It is assumed that shocks to variables of lower ordering do not contemporaneously influence variables of higher order (Choleski decomposition). But for a monthly data frequency and the inclusion of two price processes, namely equity returns and exchange rate returns, any such a causal structure is highly implausible. We therefore take a new identification approach which does not impose any zero restrictions. This method was previously used by Uhlig (2001) and Canova and De Nicolo (2002). Identification is achieved by a grid search over the space of all feasible decompositions of the variance-covariance matrix and selection of the particular one which is most in accordance with our theoretical priors. In other words we search for the moving average MA representation of the data process which accords best with the conditional correlations obtained under the hypotheses of the portfolio rebalancing channel.

We find that the data are consistent with an important role for the portfolio rebalancing channel. Our preferred variance-covariance decomposition shows that global investors repatriate foreign equity wealth after its appreciation either because of foreign equity excess returns (H1) or after an unexpected appreciation of the foreign currency (H2). Moreover, these equity flows move the exchange rate in line with a price inelastic supply of foreign exchange balances. Portfolio flow shocks appreciate the foreign exchange rate and create foreign equity market excess returns (H3).

\footnotetext{
${ }^{1}$ While gross cross-border transactions in bond and equity for the U.S. were equivalent to only 4 percent of GDP in 1975, this share increased to 100 percent in the early 1990s and has grown to 245 percent by 2000 .
} 


\section{Literature}

The empirical analysis here is closely related to recent theoretical work by Hau and Rey (2002), which provides microfoundations to the portfolio balance theory. ${ }^{2}$ Their dynamic equilibrium framework characterizes the joint dynamics of equity returns, equity flows and exchange rate returns induced by realistic constraints on the FX risk trading possibilities of international investors. According to survey evidence, international investors hedge only a minor proportion of their actual FX risk. Differential equity market performance then induces dynamic portfolio rebalancing, which in turn can move exchange rates. Hau and Rey (2002) also document that the unconditional correlation structure between relative equity returns, exchange rate returns and equity flows is supportive of such a portfolio rebalancing channel. ${ }^{3}$ The present paper extends this work to the conditional correlation structure in a VAR framework.

Similar work features in a recent study by Souriounis (2003), who uses data on net equity and bond flows, equity returns, interest rates and exchange rates to uncover dynamic links between capital flows and exchange rate movements. Souriounis (2003) documents that equity flows rather than bond flows are important in explaining exchange rates. However, his identification assumptions are not grounded in theory. Other empirical work by Froot and Ramadorai (2002) uses proprietary data on daily institutional investor currency flows. They find that these flows are highly correlated with contemporaneous and lagged exchange rate changes.

The recent empirical literature on exchange rates has highlighted a variable called currency order flow (purchaser initiated trades minus seller initiated trades) as strongly correlated with exchange rate returns (Evans and Lyons (2002), (2003a), Hau et al. (2002), Killeen et al. (2002), Rime (2001)). Order flow is sometimes interpreted as the variable through which dispersed information is aggregated and impounded in the price (Lyons (2001), Evans and Lyons (2003b)). Yet simple portfolio shifts could also give rise to order flow without any role for information asymmetries. Within the portfolio rebalancing framework and conditional on exogenous equity return and exchange rate shocks, it is plausible that net capital flows and order flows are closely aligned. Conditional on an exogenous appreciation of his foreign wealth for example, the home investor is likely to initiate the selling of foreign assets as well as the selling of foreign currency balances.

\section{Theoretical hypotheses}

The following section outlines three hypotheses with respect to the dynamics of equity returns, equity portfolio flows and exchange rate returns. Equity returns are measured as the monthly equity return differential (in local currency) between the foreign equity market index and the U.S. (home) equity market index, namely $y_{1}=E R=R(f)-R(h)$. We define equity portfolio flows as the net purchase of

\footnotetext{
${ }^{2}$ See also Pavlova and Rigobon (2003) for related work on optimal dynamic international equity holdings. Exchange rate determination in their setup is based on relative good prices and not on equity flows itself.

${ }^{3}$ See Tables 2 to 6 in Hau and Rey (2002).
} 
foreign equity by home residents minus the net purchases of home equity by foreign residents. We scale this net portfolio flow by the total equity transaction volume between home and foreign residents in both markets, and denote it by $y_{2}=F L$. Finally, exchange rate return $y_{3}=F X$ is defined as positive for a dollar appreciation.

Our first hypothesis concerns equity price innovations:

\section{H1: Portfolio rebalancing due to equity price shocks}

Foreign equity market appreciations relative to the home equity market induces a portfolio rebalancing in which the home investor reduces his foreign equity holdings in order to reduce his exchange rate risk exposure. This results in foreign equity outflows and a dollar appreciation.

Important for this portfolio rebalancing effect under differential return shocks is that exchange rate risk matters for the global investor. In a world in which all exchange rate risk is perfectly hedged (and eliminated), the global investor generally holds the world equity market and any increase in the value of foreign equity in this world market portfolio should not trigger any portfolio rebalancing. But exchange rate exposure under imperfect risk trading reduces the benefit of foreign investment. If the share of wealth in foreign asset increases, the home resident may seek to reduce his increasing FX risk exposure by selling foreign shares to foreign residents who do not face the corresponding FX risk. This aspect is formally modeled in Hau and Rey (2002), where the exchange rate and equity returns are endogenously determined under optimizing investor behavior. Their model implies a negative contemporaneous correlation between the foreign excess returns in the equity market, and the portfolio inflows into the foreign country. Formally, let $s_{1}, s_{2}$ and $s_{3}$ denote three primitive shocks to the vector $y=\left(y_{1}, y_{2}, y_{3}\right)$, then the contemporaneous correlation between $y_{1}$ and $y_{2}$ conditional on shock $s_{1}$ can be signed as $\rho_{12 \mid s_{1}}<0$. The equity portfolio flow from the foreign to the home country may also impact the equilibrium exchange rate. Repatriation of foreign equity wealth will tend to increase the demand for dollar balances and should appreciate the dollar if the currency supply is price inelastic. We can interpret the strong correlation between the exchange rate changes and FX order flow as supporting a relatively low supply elasticity in the FX market. Such a limited supply elasticity may reside in limits to intertemporal arbitrage even in a relatively liquid market as the FX market. The portfolio balance effect should therefore produce a positive correlation between foreign excess equity returns and exchange rate (dollar) appreciations, hence $\rho_{13 \mid s_{1}}>0$.

The second hypothesis concerns exchange rate innovations:

\section{H2: Portfolio rebalancing due to exchange rate shocks}

A foreign country currency appreciation increases the dollar share of assets in the foreign market. The higher overall FX risk exposure for home (U.S.) residents may induce foreign 
equity market outflows. Also, the foreign outflows should produce negative foreign equity excess returns (where returns are measured in local currency).

Like for the first hypothesis, the portfolio rebalancing effect here relies again on imperfect FX risk trading. The portfolio weights shift here not because of differential equity market performance, but because of the exchange rate change itself. Otherwise the logic is identical. The home resident holds an increasing amount of FX risk exposure after the foreign appreciation. He may therefore be less willing to hold these foreign assets and therefore we should observe foreign equity outflows. Hence, conditional on primitive shocks to the exchange rate $\left(s_{3}\right)$, we should observe a positive correlation between portfolio flows and exchange rate returns or $\rho_{23 \mid s_{3}}>0$. The second part of the hypothesis consists of this price pressure effect on relative equity market returns. Foreign equity index returns (measured in foreign currency) should be lower than U.S. (home) index returns. Formally, we obtain (conditional on an exchange rate shock) a positive contemporaneous correlation between the exchange rate returns and the foreign market excess return, that is $\rho_{13 \mid s_{3}}>0$.

The third hypothesis concerns net equity flow innovations:

\section{H3: Exchange rate and excess return changes due to equity flow innovations}

Equity flow innovations change the demand for currency balances and for equity. Foreign equity market inflows appreciate the foreign currency relative to the home currency and induce excess returns in the foreign equity market.

This hypothesis depends again on a price inelastic supply of currency balances and equity. Such limited supply elasticity can be the consequence of limited arbitrage in the FX and equity markets. Conditional on an equity flow shock, $s_{2}$, we expect a negative correlation between the net foreign equity flow and the exchange rate return as well as a positive correlation between the equity flow and the foreign excess returns. Formally, we have $\rho_{23 \mid s_{2}}<0$ and $\rho_{21 \mid s_{2}}>0$.

\section{Identification based on correlation priors}

Identification of a VAR is typically achieved by imposing a causal relationship between the variables of the data vector. Assume for example that for a particular ordering of the variables, primitive shocks to one variable affect only those higher up in the ordering, but not the reverse. Then the appropriate decomposition into primitive shocks is given by a lower triangular matrix (Choleski decomposition). But imposing such a structure is often inappropriate. It is particularly inappropriate if two or more of the variables are financial price variable like equity returns and exchange rate returns. Any equilibrium system will typically feature a reciprocal interaction between price variables even in the short run. Moreover, the equity flows data is available only at the monthly frequency. This makes any causal ordering even more problematic. Even capital flows may react to price changes over a monthly frequency. Following Uhlig (2000) and Canova and De Nicolo (2002), we therefore choose to adopt a 
less restrictive approach to the identification problem. Instead of imposing any particular identification structure, we search over all feasible MA representations of the data and choose the particular one which is most aligned with a set of theoretical correlation priors.

Formally, let the Wold MA representation of the system be

$$
y_{t}=\phi+B(L) \eta_{t}, \quad \eta_{t} \sim(0, \Sigma)
$$

where $y_{t}$ is the $3 \times 1$ vector, $\phi$ a constant and $B(L)$ a matrix polynomial in the lag operator. All orthogonal decompositions of a Wold MA representation with contemporaneously uncorrelated shocks featuring a unit variance-covariance matrix are of the form

$$
y_{t}=\phi+C(L) e_{t}, \quad e_{t} \sim(0, I)
$$

where $C(L)=B(L) \widetilde{P}, e_{t}=\widetilde{P}^{-1} \eta_{t}$, and $\widetilde{P} \widetilde{P}^{\prime}=\Sigma$. One such matrix $\widetilde{P}$ is the lower triangular matrix $P$ of the Choleski decomposition. But we can certainly generate other orthogonal decompositions of the matrix $\Sigma$ and therefore other MA representations in primitive shocks $e_{t}$. To search for all feasible MA representations, we define 3 elementary Jacobi rotations $R_{\theta_{1}}, R_{\theta_{2}}$ and $R_{\theta_{3}}$ with respect to three lower triangular elements (for $-\pi / 2<\theta_{i}<\pi / 2$ ). The first of these rotations (with respect to matrix element $(2,1))$ is given by

$$
R_{\theta_{1}}=\left(\begin{array}{ccc}
\cos \left(\theta_{1}\right) & -\sin \left(\theta_{1}\right) & 0 \\
\sin \left(\theta_{1}\right) & \cos \left(\theta_{1}\right) & 0 \\
0 & 0 & 1
\end{array}\right)
$$

The two other elementary rotation $R_{\theta_{2}}$ and $R_{\theta_{3}}$ place the sin function in matrix elements $(3,1)$ and $(3,2)$, respectively. More details are provided in the appendix. Any joint rotation $R=R_{\theta_{1}} R_{\theta_{2}} R_{\theta_{3}}$ fulfills $R R^{\prime}=I$. Hence, $P R$ also represents a decomposition of $\Sigma$ into primitive shocks and $C(L)=$ $B(L) P R$ the corresponding MA representation of $y_{t}$. We implement a grid search over all feasible combinations of Jacobi rotations and retain the particular representation $C^{*}(L)=B(L) P R^{*}$ which corresponds best to our theoretical priors.

The theoretical considerations of the previous section imply different sign restrictions $k=1,2, \ldots 6$ for the conditional correlations of the $y_{t}$ variables. The conditional contemporaneous correlation $\rho_{i j \mid s}(R)$ between variables $y_{i t}$ and $y_{j t}$ follows directly from the MA representation in orthogonalized errors as

$$
\rho_{i j \mid s}(R)=\frac{\left(C^{i}(L) s\right)\left(C^{j}(L) s\right)}{\sqrt{\left(C^{i}(L) s\right)^{2}\left(C^{j}(L) s\right)^{2}}}
$$

In order to measure correspondence with the theoretical priors, we define a penalty function $f(k, R)$ which assigns a penalty term whenever the empirical conditional correlation does not correspond to the theoretical one. For simplicity, we choose a linear penalty function which takes on the value of $f(k, R)=-\rho_{k}(R)$ if the predicted conditional correlation is positive and $f(k, R)=\rho_{k}(R)$ if the predicted conditional correlation is negative. Opposite signs for the theoretical and the empirical 
correlation therefore carry a strong penalty. A particular rotation matrix $R^{*}$ provides the most successful identification with an MA representation $C^{*}(L)=B(L) P R^{*}$ if $R^{*}$ minimizes the sum of the penalty terms $\sum_{k=1}^{6} f(k, R)$.

The identification approach here based on theoretical priors is not without circularity. We start out by postulating 6 contemporaneous conditional correlations which we sign. We then choose a decomposition of the variance-covariance matrix which maximizes the signed sum of the correlations subject to the constraint that the elementary shocks still have to generate the variance-covariance matrix of the data process. In this sense we pick the "most theory favorable" identification. But this does not predetermine the results. The decomposition of the variance-covariance matrix uses only three free parameters (three rotation angles) to fit a total of 6 theoretical moments. Rejection of one or more of the 6 conditional correlation implications by the data is therefore possible.

As a robustness check, we also examine if each conditional moment in the penalty function is necessary for obtaining the corresponding empirical moment. We therefore drop consecutively one of the 6 conditional moments in the penalty function and reproduce the impulse response on the reduced set of priors. The impulse response functions do not change qualitatively. ${ }^{4}$ In particular, each sign of the conditional moment which is excluded from the penalty function is confirmed empirically in the data based on the remaining priors.

\section{Data}

We focus our empirical analysis on bilateral equity flows between the U.S. and the 5 biggest equity markets, namely France, Germany, Japan, Switzerland and the U.K. Our portfolio flow data comes from the so-called TIC data base produced by the U.S. Treasury department. Available on a monthly frequency, the TIC data record equity transactions between U.S. residents and residents of foreign countries. The data have been carefully described by Griever et al. (2001) and allow us to compute (for each of the above countries) net purchases of foreign equity by U.S. residents, as well as net purchases of U.S. equity by foreign residents. Furthermore, we can calculate the gross transaction volumes between U.S. (home) and foreign residents for both the home and foreign equity market. Since portfolio flows have enormously increased over the last decade, we use the combined bilateral gross equity trading volumes in both the home and the foreign markets as a denominator to scale net flows. ${ }^{5}$ Net equity flows from the U.S. are therefore stated in percentages of the gross bilateral equity transaction volume. The standard deviations for the net capital flows are 0.076 for France, 0.091 for Germany, 0.091 for Japan, 0.073 for Switzerland and 0.04 for the UK.

The monthly equity return data also come from the MSCI index and are calculated for end of the month prices in local currency. Similarly, exchange rate returns are calculated based on U.S. dollar

\footnotetext{
${ }^{4}$ The exception is Japan, for which the impulse responses of the equity excess return to the exchange rate innovation changed from positive to negative when the correlation $\rho_{12 \mid s_{3}}$ is droped from the penalty function.

${ }^{5}$ Average monthly bilateral gross equity volume for the period 1990 to 2003 amounts to $\$ 19.8$ bn for France, $\$ 9.8$ bn for Germany, $\$ 24.1$ bn for Japan, $\$ 11.8$ bn for Switzerland and $\$ 95.8$ bn for the U.K.
} 
exchange rates at the end of each month where we use again MSCI data. A positive exchange rate return corresponds to a dollar appreciation relative to the foreign currency. We focus on the sample period January 1990 to September 2003. Underlying this sample selection is the fact that global equity flows became very important in magnitude only in the 1990s. Due to the creation of the euro in 1999, the last 4 years of exchange rate data coincide for France and Germany. Figure 1 provides time series plots of the three VAR variables, namely monthly foreign equity excess returns $(E R)$, the standardized U.S. equity outflows into the foreign country $(F L)$ and the exchange rate returns $(F X)$.

\section{Results}

We consecutively provide the results for innovations to the foreign equity excess return, to the equity flows and finally the exchange rate return. All graphs represent cumulative impulse response functions over 10 months for a shock of one standard deviation. Shocks and impulse response functions are always relative to the U.S., where each of the 5 countries is represented by a different row. Using the standard criteria, we found that an $\mathrm{AR}(2)$ process provided a good fit to the data. A confidence band of 2 standard deviations was constructed based on 250 simulations of the data process.

Figure 2 provides the results for equity return shocks. The first column plots the impulse response of the equity return shock on the excess return itself. The second column plots the impulse response on the equity flows from the U.S. into the respective country and the third column characterizes the impulse response on exchange rate returns. Excess return shocks are persistent over the 10 month period for all countries. Only for the U.K. is the persistence of the equity return shock unclear. The role of foreign excess return shocks on equity portfolio flows is depicted in column 2. Higher foreign equity market returns compared to the U.S. market come with negative equity flows or equity flows from the foreign country to the U.S. This evidence is in line with the portfolio rebalancing channel where investors reduce their exchange rate exposure if the foreign wealth share increases. This portfolio rebalancing occurs for all 5 countries and occurs slowly over a few months. The exchange rate impact by contrast is immediate and positive in each case (column 3). This means that the dollar appreciates as equity funds flow into the U.S. Only with respect to the British Pound can we not assert a long-run dollar appreciation. It is also interesting to look at the magnitude of the exchange rate effect. For example a 4 percent French equity excess return over a month (1 standard deviation) comes with an average 5 percent equity outflow from France to the U.S., which amounts to approximately 1 billion dollar (relative to a monthly gross volume of 20 billion dollars) and leads to a 2 percent dollar appreciation.

It is also interesting to examine the impulse response functions for an equity flow innovation into the foreign country (Figure 3). The flow innovations produce persistent foreign equity market excess returns in each of the 5 countries. The flow innovations are persistent as shown in the second column and so is their impact on the exchange rate. Portfolio outflows from the U.S. into the foreign equity 
market depreciate the dollar persistently and significantly in all 5 country cases. This result supports the idea that international equity portfolio shocks move exchange rates and influence equity excess returns.

The third type of shock concerns exchange rate innovations. Figure 4 features the respective impulse response functions. A dollar appreciation relative to the foreign currency leads to U.S. equity outflows into each of the 5 countries as shown in column 2. This is again consistent with a portfolio balancing channel, where equity is reallocated away from the appreciating foreign market. At the same time the foreign market registers an excess return.

Finally, we can undertake a variance decomposition for the three variables. Equity flow shocks and relative equity return shocks explain between 10 and 20 percent of the exchange rate variance. Moreover, this rate increases to 20 percent for all 5 countries in the subsample period 1998 to 2004 as shown in Figure 5. This amounts to an astonishingly high rate given the widespread failure of traditional macro variables in explaining exchange rate variations over the monthly horizon. The variance decomposition does not depend on the identification procedure adopted here and highlights the new important role of equity markets for exchange rate dynamics.

\section{Conclusions}

The paper investigates whether the international data on equity market returns, equity portfolio flows and exchange rate returns are consistent with a dynamic rebalancing of foreign equity positions on the part of global investors. We hypothesized that a larger wealth share held in foreign assets after either foreign equity market excess returns (H1) or a foreign currency appreciation (H2) may trigger a reallocation of equity funds away from the foreign country to the U.S. and a simultaneous dollar appreciation. Underlying this mechanism is the increased FX exposure of the global investor if FX risk trading is imperfect. Moreover, portfolio flow shocks into the foreign country directly depreciates the dollar and creates foreign equity excess returns (H3).

We find that the data are consistent with all three of these hypotheses. To arrive at this conclusion, we use an identification procedure which does not require any causal ordering of the primitive shocks. The low frequency nature of the portfolio flows and the inclusion of two price variables in the VAR appear inconsistent with any particular causal ordering. Instead, we undertake the variance-covariance decomposition in accordance with our theoretical priors concerning 6 different contemporaneous conditional correlations of the data process. We choose the particular MA representation in orthogonal shocks which is "most favorable" to the theory. This most favorable MA representation fulfills all three hypotheses for each of the 5 countries. The data are therefore consistent with an important role of the portfolio rebalancing channel to explain exchange rate and equity returns. They are also consistent with a persistent exchange rate and equity price impact of equity flow innovations. 


\section{References}

[1] Branson, William H.; and Dale W. Henderson. "The specification and influence of asset markets", in Jones, R. and P. Kenen, eds., Handbook of International Economics, North-Holland, 1985.

[2] Canova, Fabio; and Gianni De Nicolo. "Monetary disturbances matter for business fluctuations in the G-7", Journal of Monetary Economics, 2002, 49, pp. 1131-1159.

[3] Evans, Martin; and Richard Lyons. "Order flow and exchange rate dynamics', Journal of Political Economy, 2002,

[4] Evans, Martin; and Richard Lyons. "How is macro news transmitted to exchange rate", 2003a, NBER WP 9433.

[5] Evans, Martin; and Richard Lyons. "A New Micro Model of Exchange Rate Dynamics", 2003b, mimeo, UC Berkeley and Princeton University.

[6] Froot, Kenneth; and Tarun Ramadorai. "Currency Returns, Institutional Investors Flows, and Exchange Rate Fundamentals", 2002, NBER WP 9101.

[7] Griever, William L.; Lee, Gary A.; Warnock, Francis E.; and Chad Cleaver. "The U.S. System for Measuring Cross-Border Investment in Securities: A Primer with a Discussion of Recent Developments", Federal Reserve Bulletin, October 2001, Vol. 87(10), pp. 633-651.

[8] Hau, Harald; William Killeen; and Michael Moore. "How has the euro changed the foreign exchange market?", Economic Policy, 2002, 34, April, 151-177.

[9] Hau, Harald; and Hélène Rey. "Exchange Rates , Equity Prices and Capital Flows", 2002, NBER WP 9398.

[10] Killeen, William; Richard Lyons; and Michael Moore. "Fixed versus flexible: lessons from the EMS order flow", 2002, NBER WP 8491.

[11] Kouri, Pentti J. K. "Balance of Payment and the Foreign Exchange Market: A Dynamic Partial Equilibrium Model", in Jagdeep Bhandari and Bluford Putnam, eds., Economic Interdependance and Flexible Exchange Rates, MIT Press, 1982, pp. 116-156.

[12] Lyons, Richard. "The Microstructure Approach to Exchange Rates", MIT Press, 2001.

[13] Pavlova, Anna; and Roberto Rigobon. "Asset Prices and Exchange Rates", 2003, NBER WP 9834.

[14] Rime, Dagfinn. "Trading in foreign exchange markets", 2001, PhD Thesis, Norwegian School of Management. 
[15] Souriounis, Gregorios. "Uncovering the Dynamic Links of Capital Flows and Exchange Rates", 2003, mimeo LBS.

[16] Uhlig, Harald. "What are the effects of monetary policy on output? Results from an agnostic identification procedure", 2001, mimeo Humboldt University. 


\section{Appendix}

Assume the vector $y_{t}=(E R, F L, F X)^{\prime}$ has an AR representation

$$
A(L)\left(y_{t}-\phi\right)=\eta_{t},
$$

with $A(L)=1+A_{1} L+A_{2} L^{2}+\ldots A_{q} L^{q}$, and $3 \times 3$ matrices $A_{1}, A_{2}, \ldots A_{q}$. Furthermore, $E\left(\eta_{t} \eta_{t}^{\prime}\right)=\Sigma$. Let the Wold MA representation be given by

$$
y_{t}=\phi+A(L)^{-1} \eta_{t}=\phi+B(L) \eta_{t}
$$

We first estimate the coefficients $\widehat{B}(L)$ and the matrix $\widehat{\Sigma}$. One possible decomposition of the matrix $\widehat{\Sigma}=P P^{\prime}$ is the Choleski decomposition where $P$ is a lower triangle matrix. For orthogonal innovations, $e_{t} \sim(0, I)$ with $e_{t}=P^{-1} \eta_{t}$, we have $E\left(\eta_{t} \eta_{t}^{\prime}\right)=E\left(P e_{t} e_{t}^{\prime} P^{\prime}\right)=E\left(P P^{\prime}\right)=\Sigma$, and $C(L)=B(L) P$ is one possible MA representation of $y_{t}$.

$$
y_{t}-\phi=B(L) \eta_{t}=B(L) P P^{-1} \eta_{t}=B(L) P e_{t}=C(L) e_{t}
$$

Generally, we want to search over the set of all matrices $\widetilde{P}=P R$ which form a valid MA representation with $P R(P R)^{\prime}=\widehat{\Sigma}$. This search is carried out through a combination of Jacobi rotations. We can define three distinct Jacobi rotations matrices (for $-\pi / 2<\theta_{i}<\pi / 2$ ) as

$$
\begin{aligned}
R_{\theta_{1}}= & \left(\begin{array}{ccc}
\cos \left(\theta_{1}\right) & -\sin \left(\theta_{1}\right) & 0 \\
\sin \left(\theta_{1}\right) & \cos \left(\theta_{1}\right) & 0 \\
0 & 0 & 1
\end{array}\right) \\
R_{\theta_{2}}= & \left(\begin{array}{ccc}
\cos \left(\theta_{2}\right) & 0 & -\sin \left(\theta_{2}\right) \\
0 & 1 & 0 \\
\sin \left(\theta_{2}\right) & 0 & \cos \left(\theta_{2}\right)
\end{array}\right) \\
R_{\theta_{3}}= & \left(\begin{array}{ccc}
1 & 0 & 0 \\
0 & \cos \left(\theta_{3}\right) & -\sin \left(\theta_{3}\right) \\
0 & \sin \left(\theta_{3}\right) & \cos \left(\theta_{3}\right)
\end{array}\right)
\end{aligned}
$$

Any joint rotation $R=R_{\theta_{1}} R_{\theta_{2}} R_{\theta_{3}}$ fulfills $R R^{\prime}=I$. Hence, $P R$ also represents a decomposition of $\widehat{\Sigma}_{0}$ into primitive shock and $C(L)=B(L) P R$ the corresponding MA representation of $y_{t}$.

These different MA representations imply different impulse response functions and different correlation structures between the variables of $y_{t}$. Let $s$ be a vector picking the impulse response to a particular primitive shock $e_{t}$ (for example $s_{1}=(1,0,0)$ for $e_{1 t}$ ). The correlation of variable $y_{i t}$ and $y_{j t}$ conditional on a shock of type $s$ follows as

$$
\rho_{i j \mid s}(R)=\frac{\left(C^{i}(L) s\right)\left(C^{j}(L) s\right)}{\sqrt{\left(C^{i}(L) s\right)^{2}\left(C^{j}(L) s\right)^{2}}}
$$


where $C^{i}(L)$ denotes the row $i$ of $C(L)$. Given the definition of the vector $y_{t}$, correlations conditional on return shocks have $s_{1}=(1,0,0)$, those conditional on flow shocks have $s_{2}=(0,1,0)$, and those conditional on exchange rate shocks have $s_{3}=(0,0,1)$.

Economic theory provides prior information about $k=1,2, . .6$ conditional correlations $\rho_{k}$. In particular it allows us to restrict the sign of $\rho_{k}$. We can therefore define a penalty function $f($. which assigns a positive weight to MA representations in violation of theoretical sign restrictions and a negative weight if they are fulfilled. We concentrate here on a linear penalty function which gives a penalty of $f(k, R)=-\rho_{i j \mid s}(R)$ whenever a positive correlation is predicted and a penalty of $f(k, R)=\rho_{i j \mid s}(R)$ if a negative correlation is predicted. We then define $m^{3}$ grid points (with $m=90$ ) for rotation angles $\left(\theta_{1}, \theta_{2}, \theta_{3}\right) \in[-\pi / 2, \pi / 2]^{3}$ and find the rotation $R^{*}$ on the grid which minimizes the overall penalty. Formally,

$$
R^{*}=\arg \min _{\{R\}} \sum_{k=1}^{6} f(k, R) .
$$

We then report the impulse response for the MA representation given by $C(L)=B(L) P R^{*}$. 

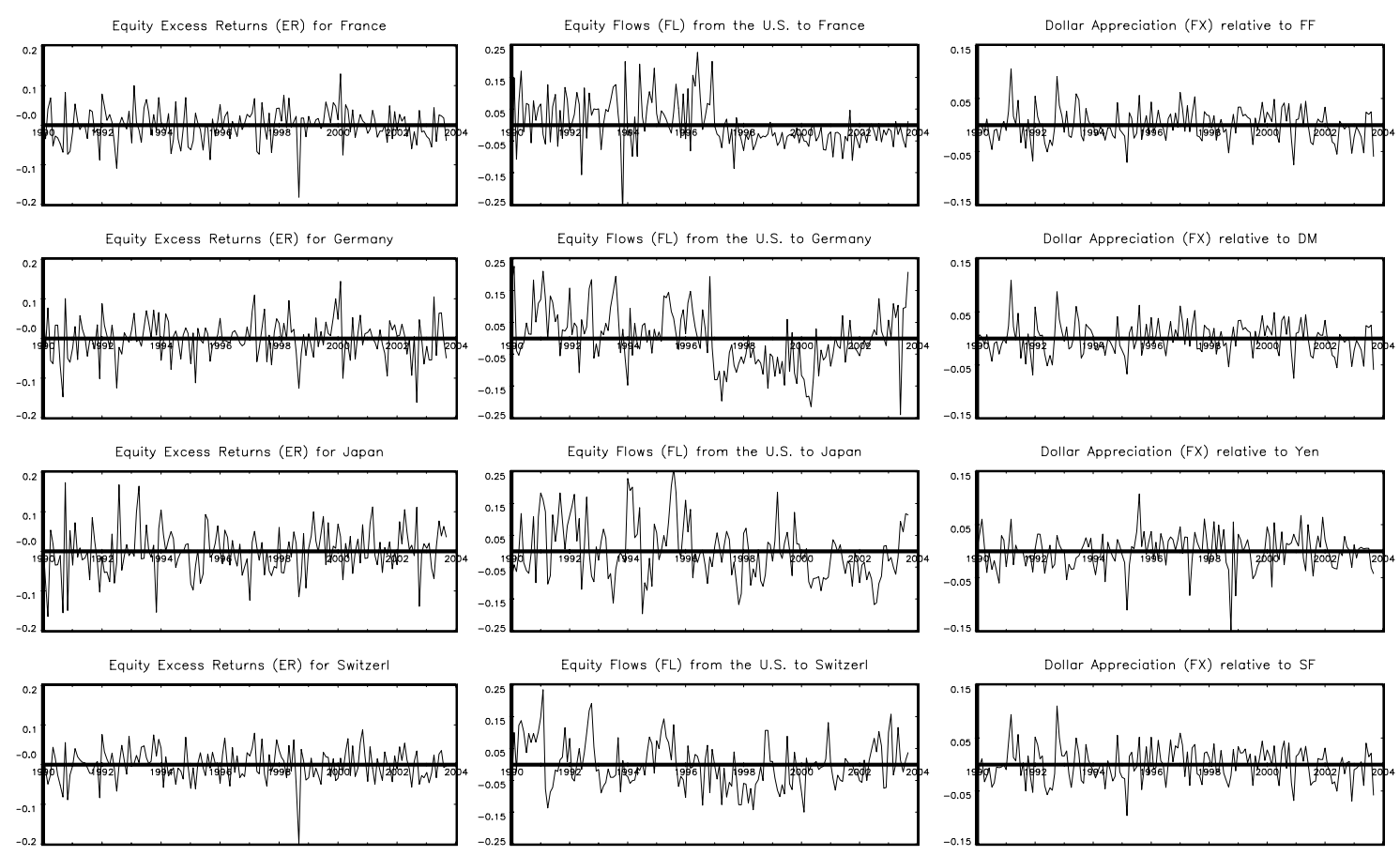

Dollar Appreciation (FX) relative to SF

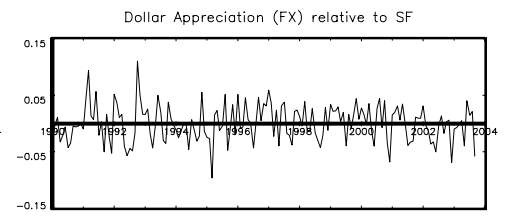

Equity Excess Returns (ER) for the UK

Equity Flows (FL) from the U.S. to the UK
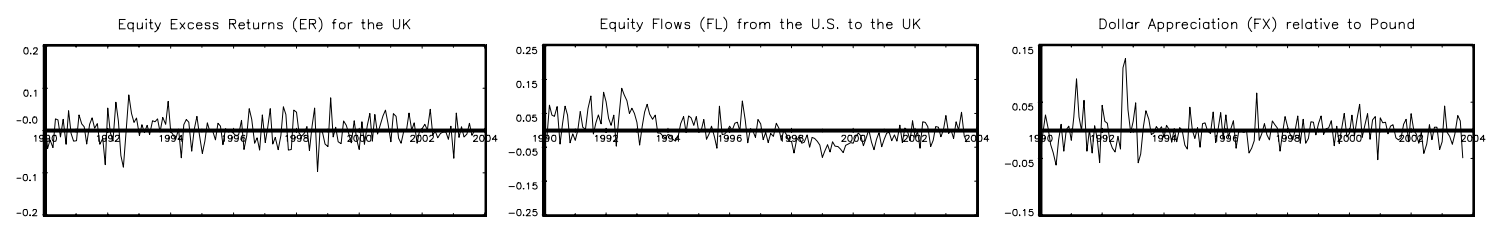

Figure 1: Shown are the monthly foreign equity excess returns (foreign market index return minus U.S. index return), the standardized U.S. equity outflows into the foreign country and the exchange rate returns (dollar appreciation is a positive return) for 5 countries, namely France, Germany, Japan, Switzerland and the U.K. The data period is January 1990 to September 2003. 


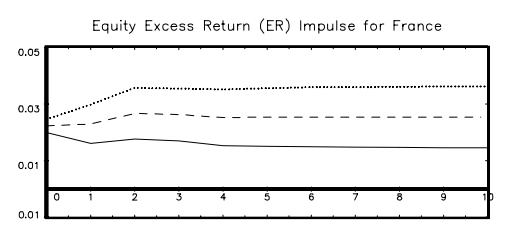

Equity Excess Return (ER) Impulse for Germany

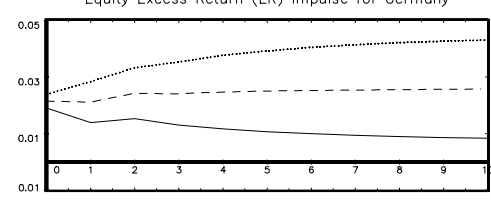

Equity Excess Return (ER) Impulse for Japan

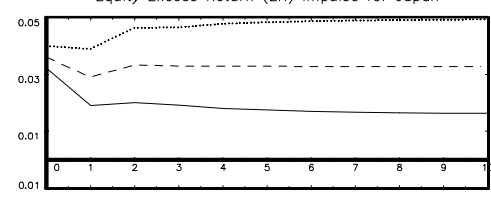

Equity Excess Return (ER) Impulse for Switzer

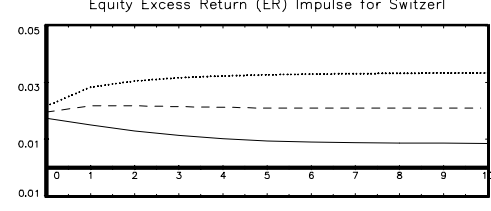

Equity Excess Return (ER) Impulse for the UK

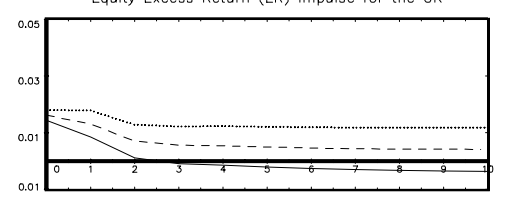

Equity Flow (FL) Impulse for France

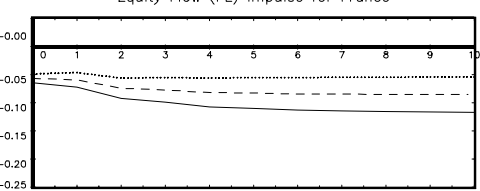

Equity Flow (FL) Impulse for Germany

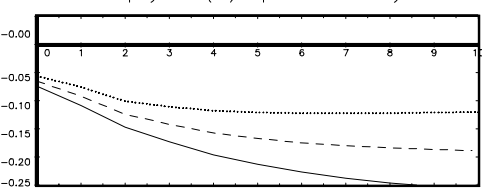

Equity Flow (FL) Impulse for Japa

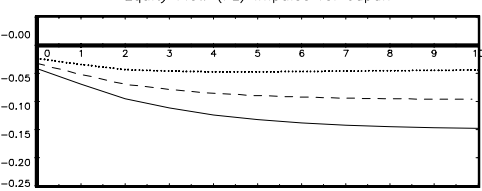

Equity Flow (FL) Impulse for Switze

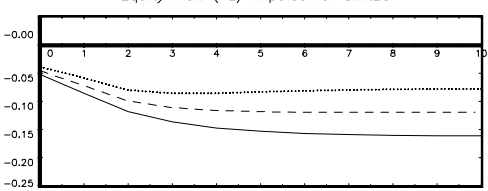

Equity Flow (FL) Impulse for the UK

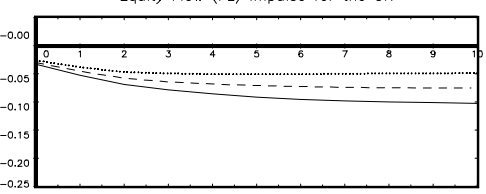

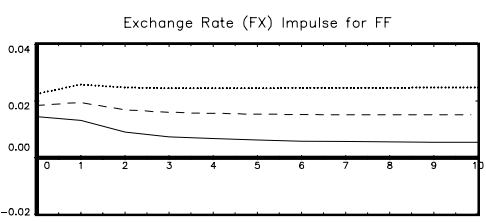

Exchange Rate $(F X)$ Impulse for DM

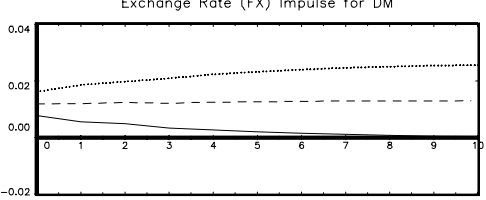

Exchange Rate (FX) Impulse for Yen

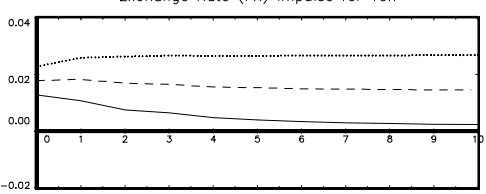

Exchange Rate (FX) Impulse for SF

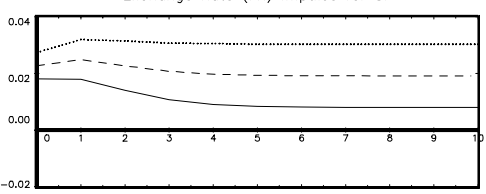

Exchange Rate (FX) Impulse for Pound

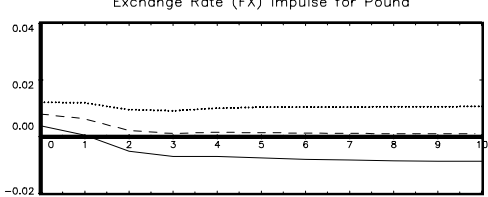

Figure 2: Shown are cumulative impulse response functions over 10 months of a foreign equity excess return shock on equity excess returns (column 1), U.S. equity outflows into the foreign country (column 2 ), and the exchange rate return (column 3 ) for the 5 sample countries (by row). Confidence intervals of 2 standard deviations are added. 


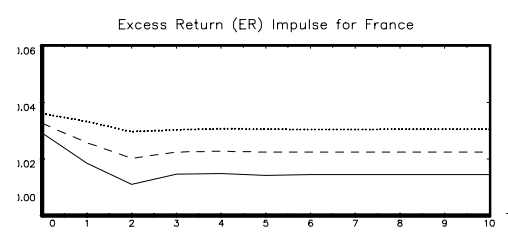

Excess Return (ER) Impulse for German

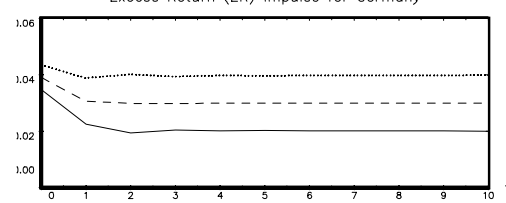

Excess Return (ER) Impulse for Japan

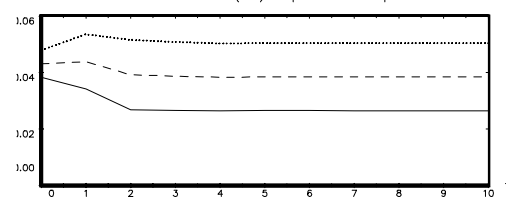

Excess Return (ER) Impulse for Switzerl

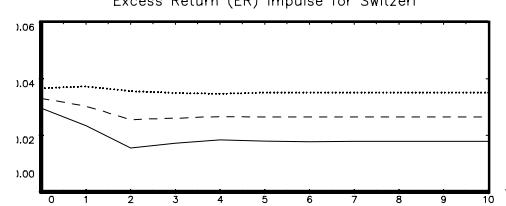

Excess Return (ER) Impulse for the UK

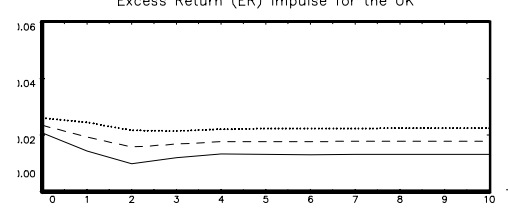

Equity Flow (FL) Impulse for France

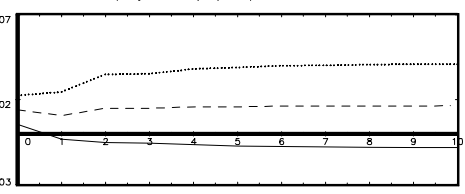

Equity Flow (FL) Impulse for Germany

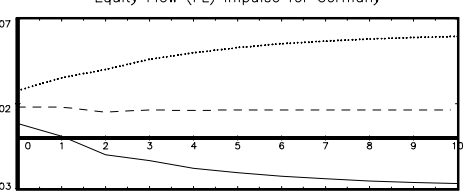

Equity Flow (FL) Impulse for Japan

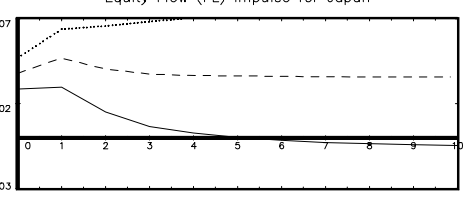

Equity Flow (FL) Impulse for Switzerl

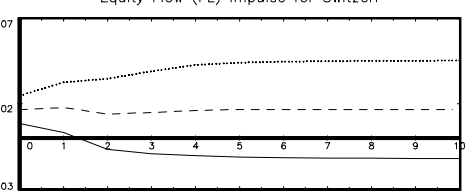

Equity Flow (FL) Impulse for the UK

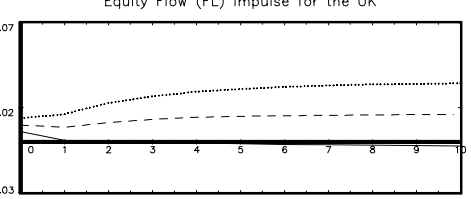

Exchange Rate (FX) Impulse for FF

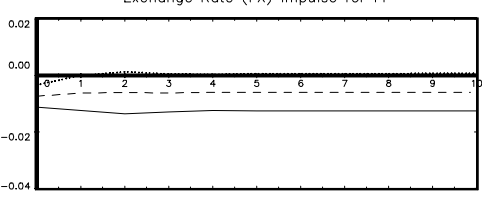

Exchange Rate (FX) Impulse for DN

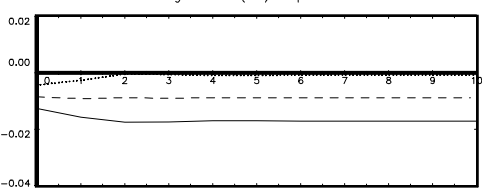

Exchange Rate (FX) Impulse for Yen

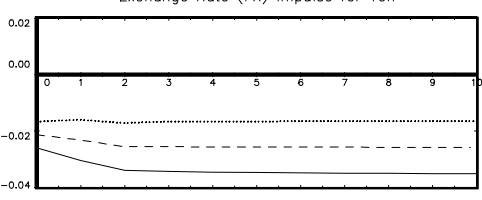

Exchange Rate (FX) Impulse for SF

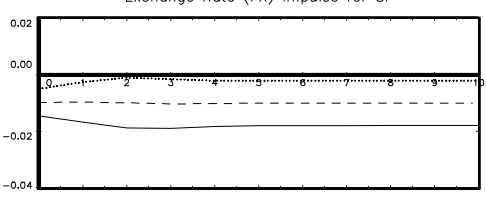

Exchange Rate $(F X)$ Impulse for Pound

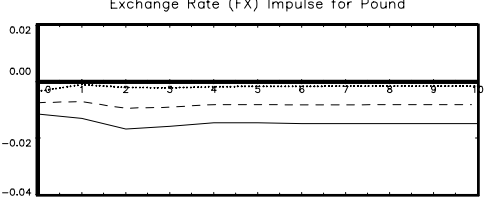

Figure 3: Shown are cumulative impulse response functions over 10 months of an equity outflow shock on foreign equity excess returns (column 1), U.S. equity outflows into the foreign country (column 2), and the exchange rate return (column 3 ) for the 5 sample countries (by row). Confidence intervals of 2 standard deviations are added. 

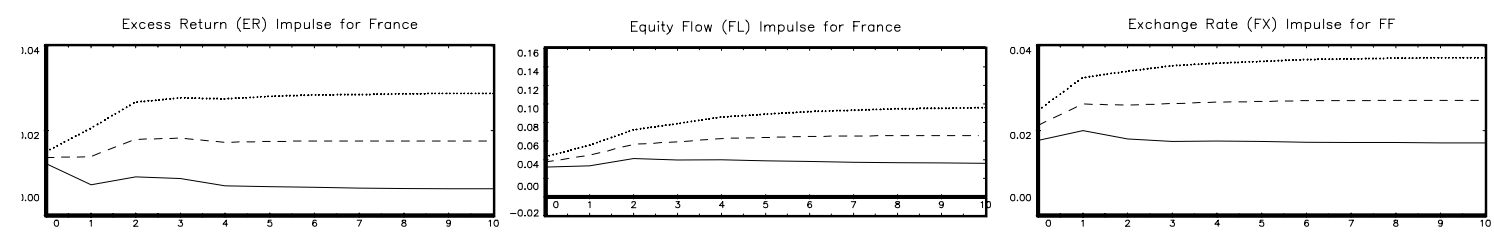

Excess Return (ER) Impulse for Germany

Equity Flow (FL) Impulse for Germany
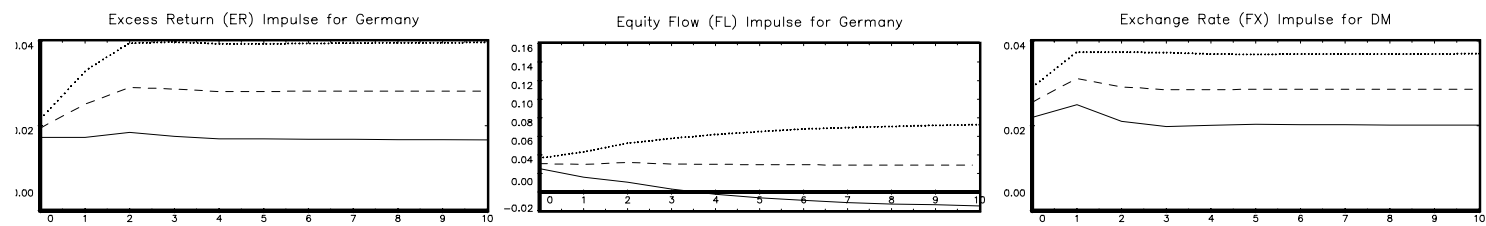

Excess Return (ER) Impulse for Japan

Equity Flow (FL) Impulse for Japan
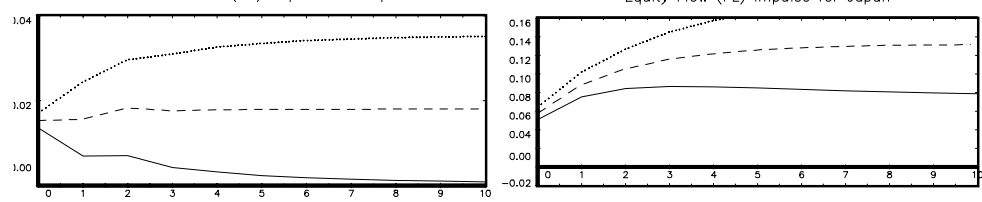

Equity Flow (FL) Impulse for Switzer

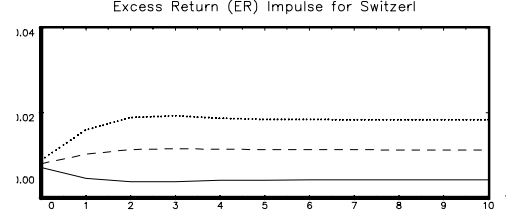

Excess Return (ER) Impulse for the UK

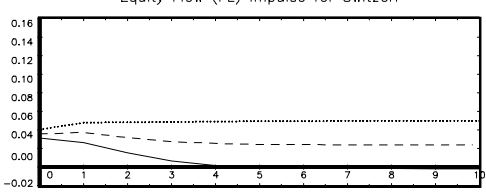

Equity Flow (FL) Impulse for the UK
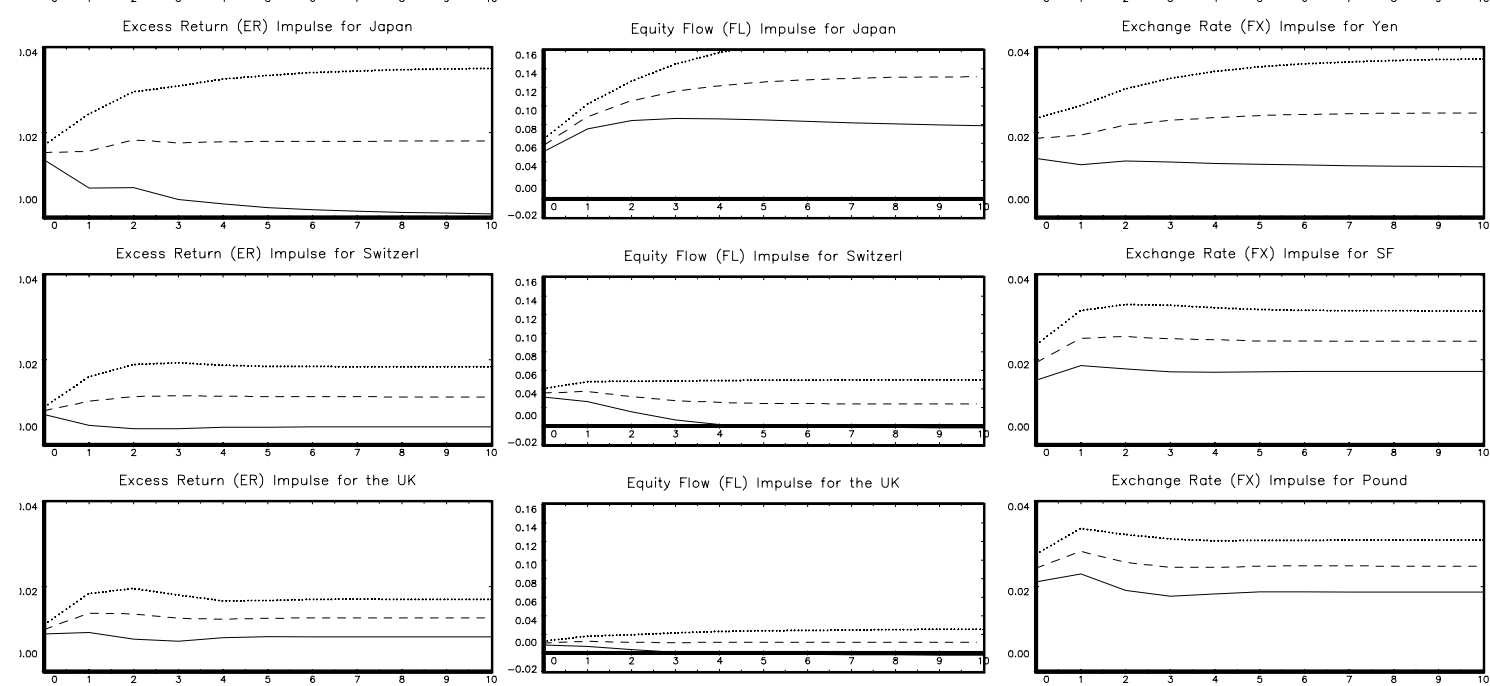

Exchange Rate $(F X)$ Impulse for SF

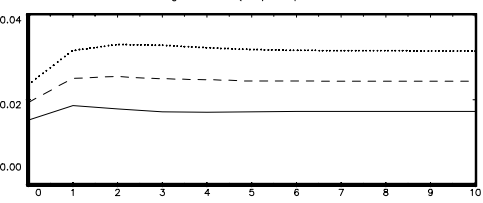

Exchange Rate (FX) Impulse for Pound

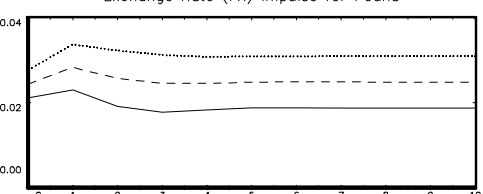

Figure 4: Shown are cumulative impulse response functions over 10 months of a FX return shock on foreign equity excess returns (column 1), U.S. equity outflows into the foreign country (column 2), and the exchange rate return itself (column 3 ) for the 5 sample countries (by row). Confidence intervals of 2 standard deviations are added. 


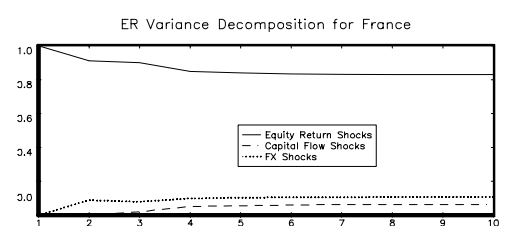

ER Variance Decomposition for Germany

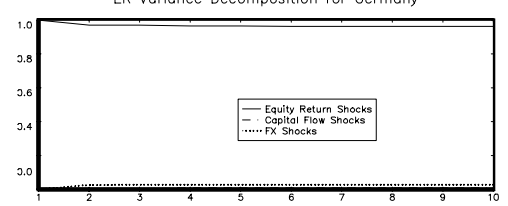

ER Variance Decomposition for Japon

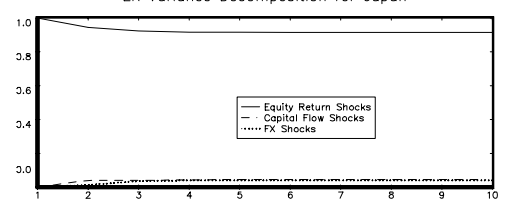

ER Variance Decomposition for Switzerl

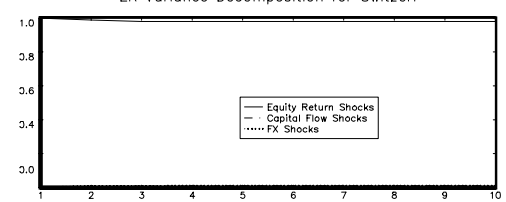

ER Variance Decomposition for the UK

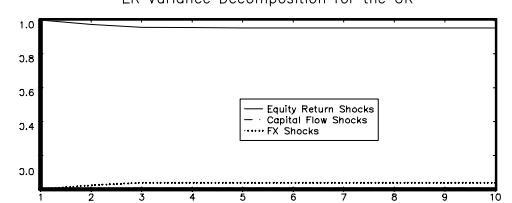

FL Variance Decomposition for Fronce

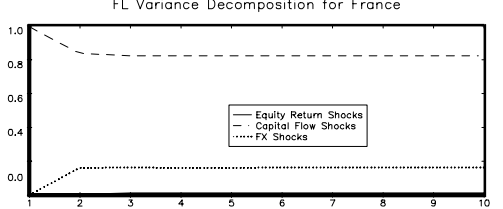

FL Variance Decomposition for Germany

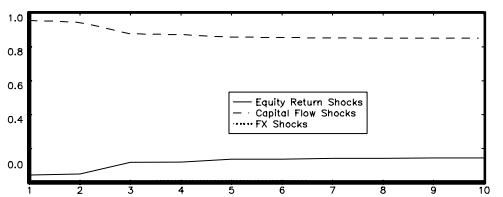

FL Variance Decomposition for Japan

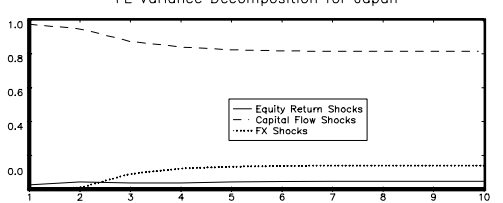

FL Variance Decomposition for Switzerl

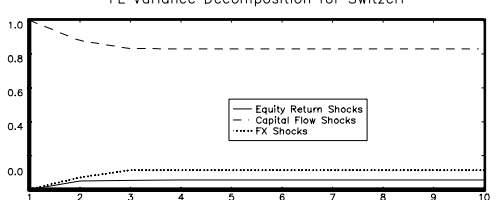

FL Variance Decomposition for the UK

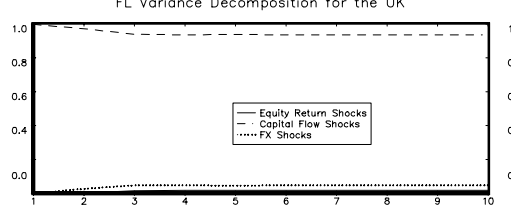

FX Voriance Decomposition for FF

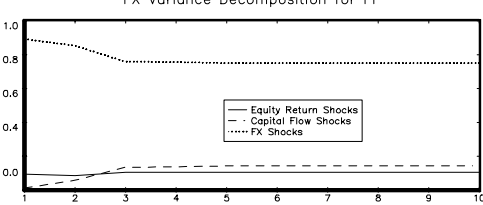

FX Variance Decomposition for DM

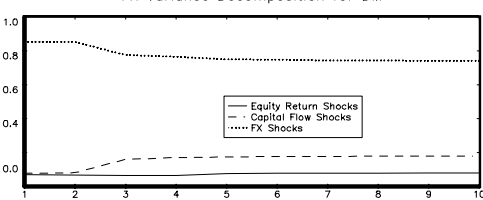

FX Variance Decomposition for Yen

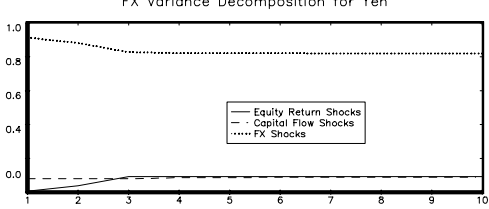

FX Variance Decomposition for SF

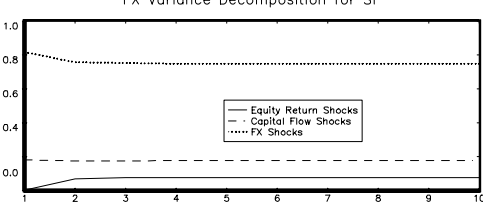

FX Variance Decomposition for Pound

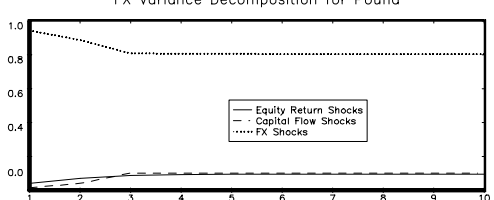

Figure 5: A variance decomposition is shown for shocks to relative equity returns (ER) (column 1), to U.S. equity outflows into the foreign country (FL) (column 2), and the exchange rate return (FX) (column 3) for the 5 sample countries (by row) over the period 1998 to 2003. In each case we plot the percentage contribution to the standard deviation of the relative equity return innovations (solid line), of the equity flow innovations (slashed line), and the FX return innovations (dotted line). 